\title{
The Expression Analysis of Complement Component C3 during Early Developmental Stages in Olive Flounder (Paralichthys olivaceus)
}

\author{
Jang-Wook Lee, Young Mee Lee, ${ }^{\dagger}$ Jeong-Ho Lee, Jae Koo Noh, Hyun Chul Kim, Choul-Ji Park, \\ Jong-Won Park, In Joon Hwang and Sung Yeon Kim \\ Genetics and Breeding Research Center, NFRDI, Geoje 656-842, Republic of Korea
}

\begin{abstract}
Fish larvae are immediately exposed to microbes from hatching to maturation of their lymphoid organs, therefore effective innate mechanisms is very important for survival in such an environment. The key component of innate immune system, C3 is central protein of all activation pathways of the complement system, leading to inflammatory reactions, such as opsonisation, chemotaxis, and cell lysis of pathogens. Although, innate mechanisms is essential for survival in the early stage of development, little is known about defence mechanisms. In this study, the alignment analysis showed that amino acid sequence of C3 from olive flounder liver EST homologous to other known C3 sequences with 73-99\% identity. Also, we examined the tissue distribution of olive flounder C3 and analyzed expression pattern from the fertilized egg until 28 days post hatching. As a result, olive flounder C3 mRNA was expressed only in the liver and the mRNA level more increased as developmental proceed during the early stage. These results may suggest that olive flounder C3 plays an important function in the early immune response of olive flounder larvae.
\end{abstract}

Key words : Olive flounder (Paralichthys olivaceus), Complement, C3, Early developmental stage, Gene expression

\section{INTRODUCTION}

The olive flounder (Paralichthys olivaceus) is one of the most important marine food source in East Asia. But, aquaculture of olive flounder is seriously affected by various diseases for production and survival. Especially, fish larvae are immediately exposed to various microbes after hatching, thereby information to effective immune system and the development of disease-resistant strains are very important for successful production and increase the survival rate (Zapata et al., 1997).

The complement system play the first line of immune defence as a key component (Nakao \& Yano, 1998). The functions of complement are numerous, but it is most well known for its capacity to removal of pathogens by creating pores in their surface membranes (Løvoll et al., 2007). Complement-mediated elimination occurs when directly activated by pathogens or antibody-antigen complexes (Holland \& Lambris, 2002). The activation by antibodyantigen complexes makes an important effector mechanism for the adaptive immune response. In addition, complement plays a role in the immune complex clearance and participates in inflammatory reactions such as opsonization, chemotaxis and cell lysis by attracting phagocytic cells to the site of injury (Boshra et al., 2006). One of the specific character of complement is its role in modulating the adaptive immune response by binding to specific receptors on mammalian lymphocyte surfaces (Fearon \&

\footnotetext{
Manuscript received 20 November 2013, Received in revised form 2 December 2013, Accepted 7 December 2013

${ }^{\dagger}$ Corresponding Author : Jeong-Ho Lee, Genetics and Breeding Research Center, NFRDI, Geoje 656-842, Republic of Korea. Tel. : +82-55-639-5811, Fax : +82-55-639-5809, E-mail : jhlee7124@korea.kr

This is an Open Access article distributed under the terms of the Creative Commons Attribution Non-Commercial License(http://creativecommons. org/licenses/by-nc/3.0) which permits unrestricted non-commercial use, distribution, and reproduction in any medium, provided the original work is properly cited.
} 
J-W Lee, YM Lee, J-H Lee, JK Noh, HC Kim, C-J Park, J-W Park, IJ Hwang, SY Kim

Locksley, 1996). Complement thereby provides an important link between adaptive and innate immune responses.

Complement is an essential part of the innate immune system and involves about 20-30 soluble plasma and membrane-bound proteins (Nakao et al., 1998; Sunyer et al., 1998). Pathogen invasion trigger the activation of complement components with a wide range of function. It has been demonstrated that mammalian blood monocytes and tissue macrophages are function of synthesizing a widely various complement components such as $\mathrm{C} 1, \mathrm{C} 2$, C3, C4, C5, factor B, D, H and I (Nathan, 1987). Complement activation can take place through three pathways which the classical complement activation pathway (CCP), the alternative complement pathway (ACP) and the lectin complement pathway (LCP). Complement is initiated by individual or combination of activation pathways and activated by binding of mannose binding lectin (MBL) to carbohydrate structures on microbes (Holland \& Lambris, 2002; Ikeda et al., 1987; Matsushita \& Fujita, 1995).

C3 is the best characterized component of complement system, playing a central role in all activation pathways. Mammalian C3 is a glycoprotein which composed of two disulfide linked chains ( $\alpha$ and $\beta$ ), containing an intrachain thioester bond in the $\alpha$-chain (Lange et al., 2004a). It can covalently binds with many target cells and participates in control of cell adhesion or cell-to-cell communication (Del Rio-Tsonis et al., 1998). In previous studies, C3 has been identified in primitive protostome species (Zhu et al., 2005) as well as in invertebrate deuterostome species, including echinoderms (Al-Sharif et al., 1998) and tunicates (Smith et al., 1999; Nonaka, 2004). In teleost fish, C3 has been isolated in olive flounder (Aoki et al., 1999), Atlantic cod (Lange et al., 2004a), Atlantic salmon (Martin et al., 2002), rainbow trout (Zakadis et al., 2001), halibut (Lange et al., 2004a), carp (Nakao et al., 2000), seabream (Sunyer et al., 1997), zebrafish (Gongora et al., 1998) and wolffish (Abelseth et al., 2003).

The C3 has been studied with immunohistochemical and real-time PCR analysis in several developmental stages in Atlantic cod (Lange et al., 2004b) and Atlantic halibut (Lange et al., 2004c), and Atlantic salmon (Løvoll et al., 2007). Also, olive flounder $C 3$ gene has been reported that expressed sequence tags (ESTs) (Aoki et al., 1999), microarray analysis (Byon et al., 2006), vaccination induced expression (Dumrongphol et al., 2009) and promoter study using transgenic zebrafish (Yazawa et al., 2005). Although the complement system has been reported in some fish, considerably less is known about the mRNA and protein expression of C3, especially in the early developmental stage. Therefore, we investigate the tissue-specific expression and expression pattern analysis in early development of C3 from the fertilized egg until 28 days post hatching.

\section{MATERIALS AND METHODS}

\section{Sample preparation}

Olive flounder eggs and larvae was obtained from Genetics and Breeding Research Center, National Fisheries Research and Development Institute (NFRDI; Geoje, Republic of Korea). Fertilised eggs from cultured flounder were hatched at $18^{\circ} \mathrm{C}$ in 5 tons flow through under a natural photoperiod. Different four stages of embryo $(\sim 0.92 \mathrm{~mm})$ including fertilized egg (F), molura (E1), blastula (E2), late neurula (E3) and ten larval stages ( 11.34 mm) including 0 to 28 days post hatching (dph) (H0, H1, H2, $\mathrm{H} 3, \mathrm{H} 4, \mathrm{H} 5, \mathrm{H} 7, \mathrm{H} 14, \mathrm{H} 21$ and H28) fish kept at $18^{\circ} \mathrm{C}$ in the sea-water tank. And the sample was prepared from various tissues including kidney, spleen, gill, liver, brain, muscle, fin and eye obtained from adult olive flounder (2-year-old; $n=3$ ). These ontogenic samples were observed and determined developmental stage under a microscope system at various magnification. The sample of 10 randomly selected fishes were collected and immediately frozen in liquid nitrogen, and stored at $-80^{\circ} \mathrm{C}$ until RNA extraction.

\section{RNA extraction and cDNA synthesis}

Total RNA was extracted using the Trizol Reagent (Invitrogen) according to the manufacturer's protocol. The total RNA concentration was quantified by spectrophoto- 
The Expression Analysis of Complement Component C3 in Olive Flounder

meter and $1 \mu \mathrm{g}$ of total RNA was used for reverse transcribed into cDNA using First Strand cDNA synthesis kit (Roche). The amplification was performed with AmpliTag Gold DNA Polymerase (Applied Biosystems) in thermal Cycler (Applied Biosystems) using the following parameters: denaturation at $95^{\circ} \mathrm{C}$ for $10 \mathrm{~min}$ and 35 cycles of reactions of denaturation at $98^{\circ} \mathrm{C}$ for $10 \mathrm{sec}$, annealing at $58^{\circ} \mathrm{C}$ for $30 \mathrm{sec}$, and elongation at $72^{\circ} \mathrm{C}$ for $30 \mathrm{sec}$. An aliquot of each PCR product was subjected to $1.2 \%(\mathrm{w} / \mathrm{v})$ agarose gel electrophoresis and visualized by staining with ethidium bromide.

All the primers were designed using Primer3 (Rozen \& Skaletsky 2000). The level of C3 expression was detected using specific primers (C3-F: 5'-GTA CCT CAT CAT GGG CAC ATC-3' and C3-R: 5'-GTG CTC CTC GGT TTG ACA CT-3'). Housekeeping gene was amplified using beta-actin; 5'-GAG CGT GGC TAC TCC TTC AC-3' and 5'-AGG AAG GAA GGC TGG AAG AG-3', Genbank accession number (CX725848), forward and reverse primers, respectively.

\section{Real-time PCR analysis}

To evaluate mRNA levels of C3, primers were specifically designed to detect and quantify cDNA sequences without detecting genomic DNA. The real-time PCR reactions was monitored with melting curve analysis using 7500 software (version 2.0.5). Amplification efficiency was determined by a serial dilutions. All experiments were repeated in tri-replicate. Each reactions displayed an efficiency $95.9 \%\left(\mathrm{R}^{2}=0.997\right)$ and $97 \%\left(\mathrm{R}^{2}=0.999\right)$, C3 and beta-actin, respectively.

Real-time PCR reaction mixture contained $2 \mu \mathrm{l}$ of diluted sample, PCR primer and the Power SYBR Green PCR Master Mix (Applied Biosystems). Amplification was carried out as follows: denaturation at $95^{\circ} \mathrm{C}$ for 10 min and 35 cycles of reactions of denaturation at $95^{\circ} \mathrm{C}$ for $10 \mathrm{sec}$, annealing at $58^{\circ} \mathrm{C}$ for $30 \mathrm{sec}$, and elongation at $72^{\circ} \mathrm{C}$ for $45 \mathrm{sec}$. Thermal cycling and fluorescence detection were conducted using the ABI7500 (Applied Biosystems).
The raw threshold cycle (Ct) represents the PCR cycle at which an increase in reporter fluorescence baseline signal can first be detected. The ratio between the housekeeping gene content in standard samples $\left(10^{6}\right.$ copies) and test samples were defined as the normalization factor. The fold changes of C3 mRNA in different developmental stages or tissues were calculated using standard deltadelta-Ct method (Pfaffl, 2001).

\section{Bioinfomatic analysis}

Bioinfomatic analysis was conducted to determine gene identities using Gene Master software (Ensoltek, Beaverton, USA). ESTs were assembled in clusters of contiguous sequences (conting) using ICA tools program (Parsons, 1995). Gene annotation procedures and homology searches of the sequenced ESTs have been locally done by BLASTX for amino acid similarity comparisons. Matches with the expect value $(E)$ less than $1.0 \times \mathrm{e}^{-4}$ were considered to be significant. Multiple alignments of the amino acid were constructured using the ClustalW program using default parameters (Thompson, 1994) and visualized with MEGA 3.1 (Kumar et al., 2004).

\section{Statistical analysis}

The data are presented as the mean \pm S.D. The mRNA levels of C3 were expressed as a ratio to those beta-actin, which was simultaneously amplified as an internal control for each cDNA. The data was statistically analized by one-way ANOVA after arcsine transformation when needed, and followed by Duncan's multiple-range test. All experiments were performed two or three times on different batches and differences were considered statistically significant at $P<0.05$.

\section{RESULTS}

\section{Sequence analysis of olive flounder C3}

In previous study, we constructed a cDNA library using liver samples of olive flounder and we screened 260 clones (unpublished data). The homologs search of the EST sequence with the corresponding amino acid sequence 
was examined using BLASTX search of GenBank and sequence alignment was performed with the ClustalW program (http://www.ch.emb net.org/software/ClustalW. html). A GenBank search showed that Liver-1-D12 was revealed to be homologous with olive flounder C3 (BAA88901.1) and has significant high identity above 99\%. When compared to C3 of other species were $84 \%$ with Atlantic halibut (AAW72004.1), 80\% with miiuy croaker (AFC89899.1), 80\% with orange-spotted grouper (ADU33222.1), 76\% with yellow perch (ACO82018.1), 75\% with spotted wolffish (CAC29154.1), 74\% with gilthead sea bream (ADM13620.1), and 73\% with green swordtail (AEJ08067.1) (Fig. 1). Alignment of amino acid residues of the olive flounder C3 gene with those from other fish indicate a high degree of conservation in the amino acid sequence, therefore we suggest that olive flounder C3 will be similar function another C3.

\section{Expression study of olive flounder $\mathrm{C} 3$}

In previous study, Lange et al. (2004b) described that C3 mRNA was expressed in various tissues including the yolksac, liver, brain, kidney, muscle, eye, notochord, stomach, intestines, pancreas, heart and gills and detected throughout the early larvae period in Atlantic cod (Gadus morhua L.) using immunohistochemistry analysis method. Also, Løvoll et al. (2007) reported that the expression of C3 mRNA was observed the liver and extrahepatic tissues including the heart, muscle, gonads, intestine, skin, kidney, pylorus, spleen and gill in Atlantic salmon. On the other hand, Yazawa et al. (2005) reported that C3 gene was only expressed in the liver that stimulated with lipopolysaccharide (LPS) from olive flounder.

To investigate the tissue specific expression of the complement component C3 gene, oligonucleotide specific primers were designed according to previously reported C3

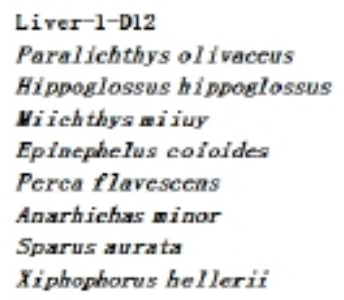

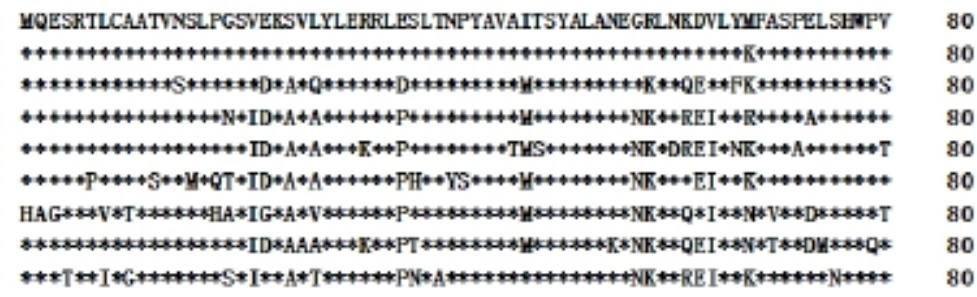

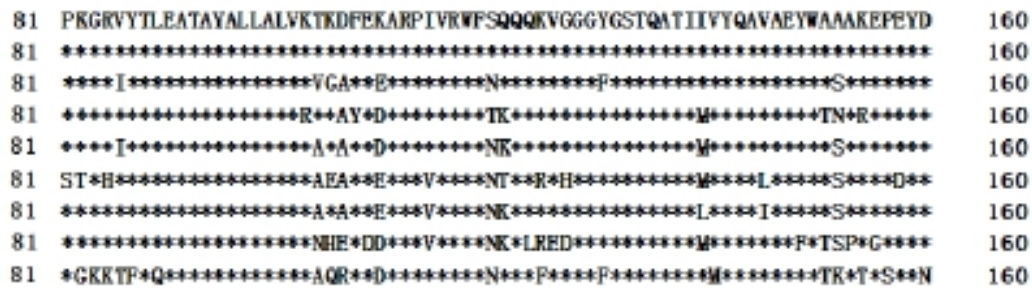

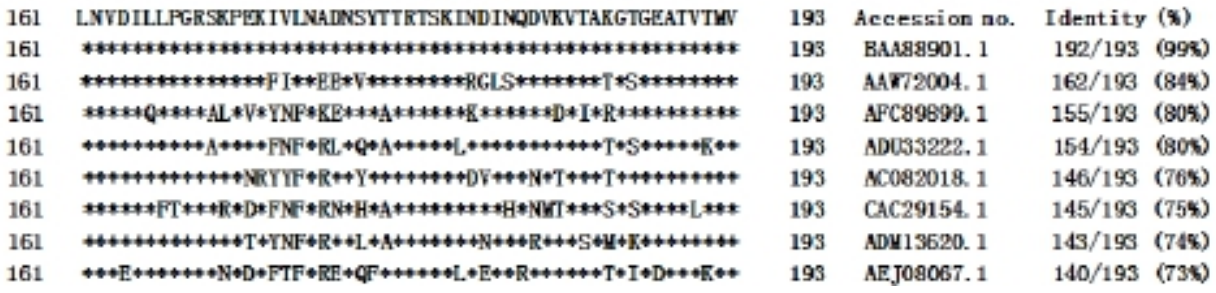

Fig. 1. The deduced amino acid sequence alignment of $\mathbf{C} 3$ gene in olive flounder. The C3 sequences is aligned with the several species. Identical amino acid residues are displayed by Asterisk $\left(^{*}\right)$. It is indicates the invariant and conserved residues in C3. The percentages in parentheses indicate the overall amino acid identities. Genbank accession no.: Paralichthys olivaceus (BAA88901.1), Hippoglossus hippoglossus (AAW72004.1), Miichthys miiuy (AFC89899.1), Epinephelus coioides (ADU33222.1), Perca flavescens (ACO82018.1), Anarhichas minor (CAC29154.1), Sparus aurata (ADM13620.1) and Xiphophorus hellerii (AEJ08067.1). 
The Expression Analysis of Complement Component C3 in Olive Flounder

gene in olive flounder (GenBank accession no. AB021653), and then we examined by RT-PCR using isolated various tissues from 2-year-old healthy olive flounder. The mRNA expression level of olive flounder C3 was compared with beta-actin as the internal control in various tissue. The mRNA of olive flounder C3 gene was absolutely expressed only the liver, while other tissues (muscle, brain, eye, kidney, spleen, gill and fin) was not detected at all in healthy olive flounder (Fig. 2).

In order to investigate of olive flounder C3 mRNA expression during early development, we analyzed the temporal expression pattern of olive flounder C3 at the four embryos stages and ten larval stages (Fig. 3). As a result, the mRNA level of olive flounder C3 was not detected from fertilized egg (F) to blastula (E2). The olive flounder C3 expression was detected from late neurula (E3) and increased hatching step and then dropped. The lowered level significantly increased again to metamorphosis (H28). The intensity of C3 transcript was measured on the basis of late neurula stage (E3) (1.0-fold), each value has the hatching stage (H0, 10.1-fold), H1 (5.0-fold), H2 (3.2-fold), H3 (1.8-fold), H4 (3.2-fold), H5 (1.6-fold), H7 (7.8-fold), H14 (9.6-fold), H21 (19.1-fold) and H28 (20.0-fold), respectively.

Significant induction of olive flounder C3 expression was detected in hatching stage (H0), $7 \mathrm{dph}$ (H7) and 21 dph (H21). These results showed the mRNA of olive flounder C3 gene was accumulated from hatching stage to early larvae stage until $28 \mathrm{dph}$. These expression pattern of olive flounder C3 mRNA during the early developmental stage suggest a vital role of defence mechanisms during the earliest stages of life.

\section{DISCUSSIONS}

Because of the importance of primary immune response, many studies have been conducted in fish. These reports commonly indicate that complement genes play an essential

A
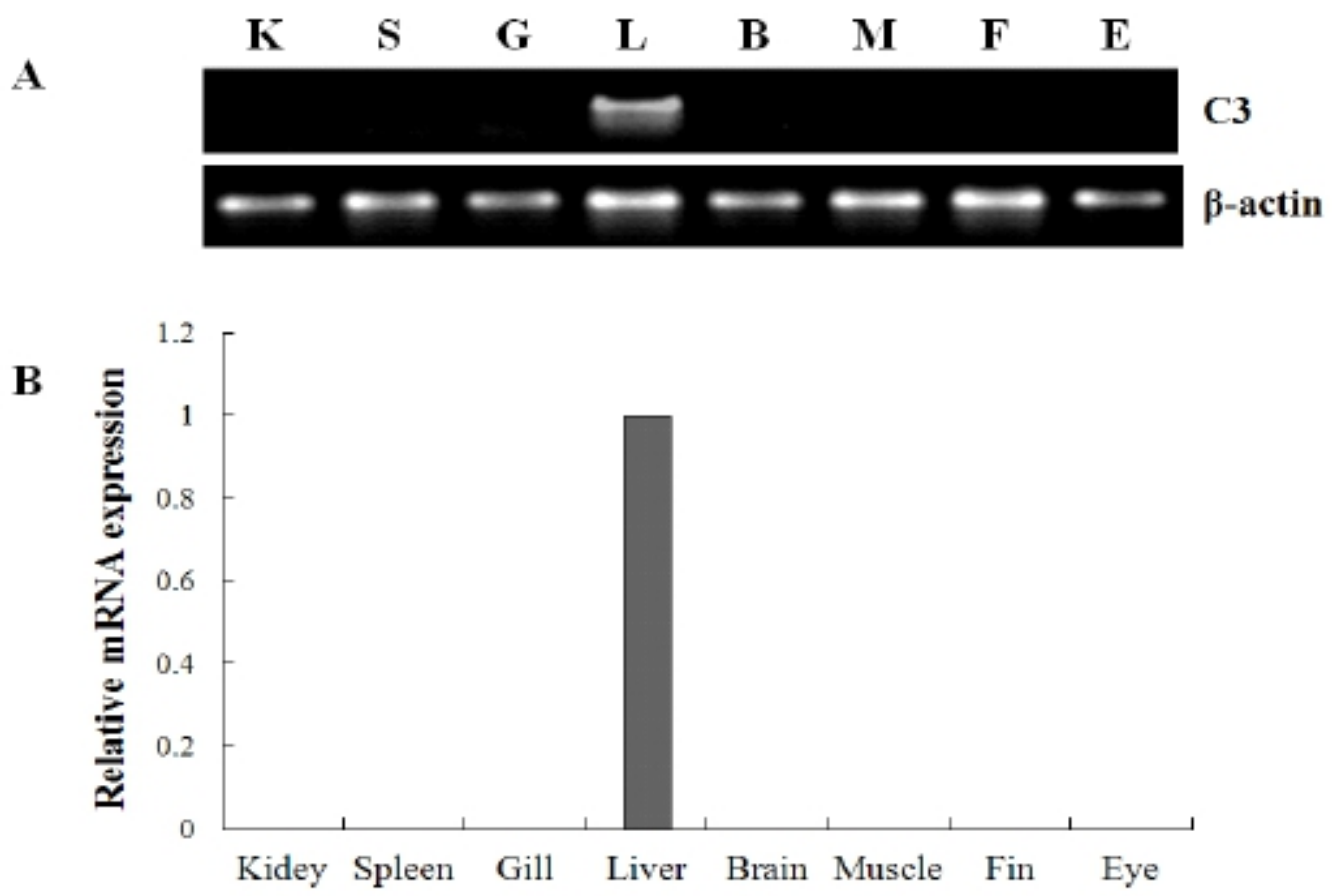

Fig. 2. Normal tissue distribution of complement component C3 mRNA in various tissues. (A) Tissue distribution of the C3 mRNA was subjected to RT-PCR analysis using 2 year-old healthy olive flounder. (B) A quantitative real-time PCR analysis was performed with equal amounts of total RNA from the tissues of healthy olive flounders. $\beta$-actin was used as an internal control. K, Kidney; S, Spleen; G, Gill; L, Liver; B, Brain; M, Muscle; F, Fin; E, Eye. 
role in altering the host of the presence of potential pathogens (Boshra et al., 2006). Among complement component, C3 play a crucial function in the early immune response of fish larvae (Løvoll et al., 2007). The amino acid sequence was compared to the corresponding part of other known C3 sequences using ClustalW, shows that similarity with olive flounder (99\%), Atlantic halibut (84\%), miiuy croaker (80\%), orange-spotted grouper (80\%), yellow perch (76\%), spotted wolffish (75\%), gilthead sea bream (74\%) and green swordtail (73\%) (Fig. 1).

Researches reported that C3 is ubiquitiously expressed various organs and their presence detected throughout the early development stages of larvae in Atlantic cod (Lange et al., 2004b) and Atlatic halibut (Lange et al., 2004c). These result are conflicted with C3 expression studies in the spotted wolffish (Abelseth et al., 2003), where C3 expression appeared to be limited only the liver. In our study, we examined the tissue distribution of olive flounder C3 using various tissues from healthy olive flounder to analyze a patterns of tissues expression. As a result, olive flounder C3 mRNA was expressed only in the liver. Our results are similar with other study in olive flounder (Yazawa et al., 2005). Yazawa et al. described that C3 gene was also expressed only in the liver that stimulated with lipopolysaccharide (LPS). The liver is a important organ with innate immunity, playing a crucial role in host defenses against pathosens. But, these distribution difference may be due to configuration of the different kinds of isotypes and perhaps more C3 isoforms exist in Atlantic cod and Atlatic halibut. Thus, it will be great interest to determine the functional diversity of C3 in teleost fish species.

Fish larvae are exposed to pathogens a long period before of time until maturation of their lymphoid organs,

A $\begin{array}{llllllllllllll}\text { F } & \text { E1 } & \text { E2 } & \text { E3 } & \text { H0 } & \text { H1 } & \text { H2 } & \text { H3 } & \text { H4 } & \text { H5 } & \text { H7 } & \text { H14 } & \text { H21 } & \text { H28 }\end{array}$

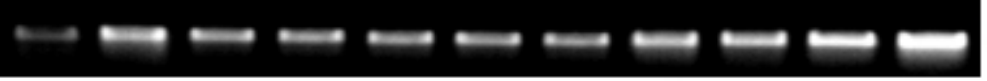

C3

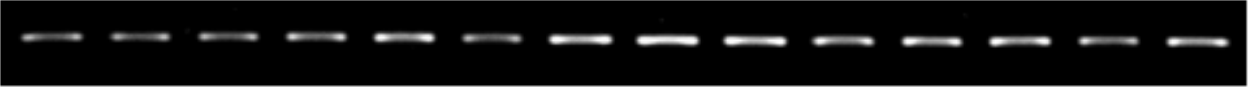

$\beta$-actin

B

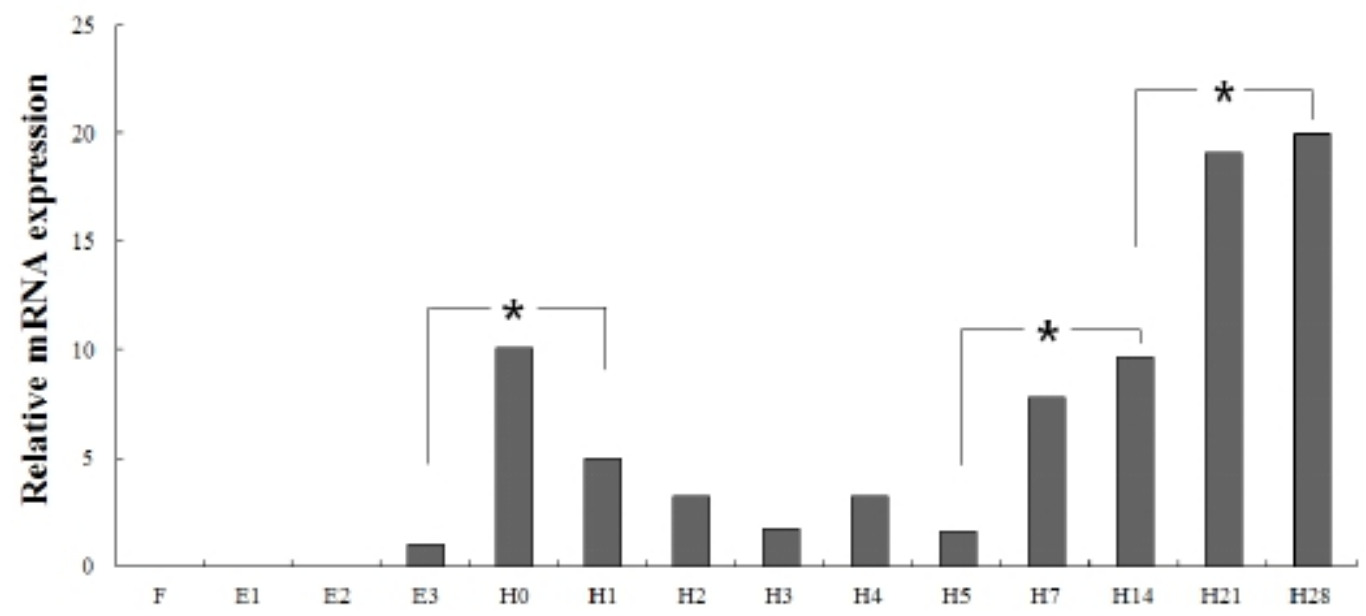

Fig. 3. Expression of complement component C3 gene at different developmental stages. (A) Larvae was harvested during post fertilization to 28 days after hatching. The RNA extracted and analyzed by RT-PCR method. (B) The mRNA expression of C3 was analyzed by real-time PCR. Different letters over each bar with the standard deviation represent significant differences one group according to unpaired matched comparisons $(* P<0.05)$. Different four stages of embryo $(\sim 0.92 \mathrm{~mm})$ including fertilized egg $(\mathrm{F})$, molura (E1), blastula (E2), late neurula (E3) and ten larval stages $(\sim 11.34 \mathrm{~mm})$ including 0 to 28 days post hatching (dph) (H0, H1, H2, H3, H4, H5, H7, H14, H21 and H28). 
The Expression Analysis of Complement Component C3 in Olive Flounder

therefore innate mechanisms may be essential for survival (Zapata et al., 1997). But, the mRNA expression analysis of C3 during the early developmental stage in olive flounder is insufficient. In our result, real-time PCR has been performed to detect the onset of C3 transcription in late neurula stage, observed the increased mostly until 28 dph. Induction of C3 mRNA was observed in hatching stage, that seems to be related with initiation a set up of immune system. Also, significant expression of C3 was detected form $7 \mathrm{dph}$ to $21 \mathrm{dph}$, this time is when the development of digestive tract and feed conversion of extruded pellet (EP). These significantly differences are indicated that immune maturation system as a growth. In our study, the results showed the mRNA of C3 gene was accumulated from hatching stage to early larvae stage until 28 dph and mostly increased during developmental proceed. In other studies, it is reported that the salmon (Løvoll et al., 2007) and rainbow trout (Løvoll et al., 2006) profiles differed after hatch by increasing and deflating expression levels, respectively. Moreover C3 has been found in several different organs and tissues of developing cod (Lange et al., 2004b) and halibut (Lange et al., 2004c) using immunohistochenistry techniques. These studies suggest that complement may play a role in the generation of different organs and not only in the defence against invading pathogens (Dalmo, 2005).

In summary, this study provides the information of C3 mRNA expression during the early developmental stage in olive flounder. Expression pattern of olive flounder C3 in tissue distribution and developmental stage shows that may play an important function in the early immune response of olive flounder larvae. It is provides the first appearance of complement component C3 decribed in the present paper and indicates a relevant role of C3 during early developmental stages of olive flounder. However, the more research is needed to the isotype and exact function of C3 during the early development.

\section{ACK NOWLEDGEMENTS}

This work was supported by a grant from the National Fisheries Research and Development Institute (NFRDI), contribution number RP-2013-BT-108.

\section{REFERENCES}

Abelseth TK, Stensvag K, Espelid S, Nygaard R, Ellingsen T, Bogwald J, Dalmo RA (2003) The spotted wolffish (Anarhichas minor Olafsen) complement component C3: isolation, characterisation and tissue distribution. Fish Shellfish Immunol 15:13-27.

Al-Sharif WZ, Sunyer JO, Lambris JD, Smith LC (1998) Sea urchin coelomocytes specifically express a homologue of the complement component C3. J Immunol 160: 2983-2997.

Aoki T, Nam B-H, Hirono I, Yamamoto E (1999) Sequences of 596 cDNA clones (565,977 bp) of Japanese flounder (Paralichthys olivaceus) leukocytes infected with Hirame Rhabdovius. Mar Biotechnol 1:477-488.

Boshra H, Li J, Sunyer JO (2006) Recent advances on the complement system of teleost fish. Fish Shellfish Immunol 20:239-262.

Byon JY, Ohira T, Hirono I, Aoki T (2006) Comparative immune responses in Japanese flounder, Paralichthys olivaceus after vaccination with viral hemorrhagic septicemia virus (VHSV) recombinant glycoprotein and DNA vaccine using a microarray analysis. Vac 9: 921-930.

Dalmo RA (2005) Ontogeny of the fish immune system. Fish Shellfish Immunol 19:395-396.

Del Rio-Tsonis K, Tsonis PA, Zarkadis IK, Tsagas AG, Lambris JD (1998) Expression of the third component of complement, C3, in regenerating limb blastema cells of urodeles. J Immunol 161:6819-6824.

Dumrongphol Y, Hirota T, Kondo H, Aoki T, Hirono I (2009) Identification of novel genes in Japanese flounder (Paralichthys olivaceus) head kidney up-regulated after vaccination with Streptococcus iniae formalin-killed cells. Fish Shellfish Immunol 26:197-200.

Fearon DT, Locksley RM (1996) The instructive role of 
J-W Lee, YM Lee, J-H Lee, JK Noh, HC Kim, C-J Park, J-W Park, IJ Hwang, SY Kim

innate immunity in the acquired immune response. Science 272:50-53.

Gongora R, Figueroa F, Klein J (1998) Independent duplications of $\mathrm{Bf}$ and $\mathrm{C} 3$ complement genes in the zebrafish. Scand J Immunol 48:651-658.

Holland MCH, Lambris JD (2002) The complement system in teleosts. Fish Shellfish Immunol 12:399-420.

Ikeda K, Sannoh T, Kawasaki N, Kawasaki T, Yamashita I (1987) Serum lectin with known structure activates complement through the classical pathway. J Biol Chem 262:7451-7454.

Kumar S, Tamura K, Nei M (2004) MEGA3: Integrated software for molecular evolutionary genetics analysis and sequence alignment. Brief Bioinform 5:150-163.

Lange S, Bambir S, Dodds WA, Magnadottir B (2004c) An immunohistochemical study on complement component C3 in juvenile Atlantic halibut (Hippoglossus hippoglossus L.). Dev Comp Immunol 28:593-601.

Lange S, Bambir S, Dodds WA, Magnadottir B (2004b) The ontogeny of complement component C3 in Atlantic cod (Gadus morhua L.)-an immunohistochemical study. Fish Shellfish Immunol 16:359-367.

Lange S, Dodds AW, Magnadóttir B (2004a) Isolation and characterisation of complement component C3 from Atlantic cod (Gadus morhua L.) and Atlantic halibut (Hippoglossus hippoglossus L.). Fish Shellfish Immunol 16:227-239.

Løvoll M, Johnson H, Boshra H, Bøgwald, Sunyer JO, Dalmo RA (2007) The ontogeny and extrahepatic expression of complement factor C3 in Atlantic salmon (Salmo salar). Fish Shellfish Immunol 23:542-552.

Løvoll M, Kilvik T, Boshra H, Bøgwald J, Sunyer JO, Dalmo RA (2006) Maternal transfer of complement components C3-1, C3-3, C3-4, C4, C5, C7, Bf and Df to offspring in rainbow trout (Oncorhynchus mykiss). Immunogenet 58:168-179.

Martin SA, Caplice NC, Davey GC, Powell R (2002) EST-based identification of genes expressed in the liver of adult Atlantic salmon (Salmo salar). Biochem Biophys Res 293:578-585.
Matsushita M, Fujita T (1995) Cleavage of the third component of complement (C3) by mannose-binding protein associated serine protease (MASP) with subsequent complement activation. Immunobiology 194:443-448.

Nakao M, Mutsuro J, Obo R, Fujiki K, Nonaka M, Yano $\mathrm{T}$ (2000) Molecular cloning and protein analysis of divergent forms of the complement component C3 from a bony fish, the common carp (Cyprinus carpio): presence of variants lacking the catalytic histidine. Eur J Immunol 30:858-866.

Nakao M, Yano T (1998) Structural and functional identification of complement components of the bony fish, carp (Cyprinus carpio). Immunol Rev 166:27-38.

Nathan CF (1987) Secretory products of macrophages. J Clin Invest 79:319-326.

Nonaka M (2004) Evolution of the complement system. Mol Immunol 40:897-902.

Parsons JD (1995) Improved tools for DNA comparison and clustering. Comput Appl Biosci 11:603-613.

Pfaffl MW (2001) A new mathematical model for relative quantification in real-time RT-PCR. Nucleic Acids Res 29, e45.

Rozen S, Skaletsky HJ (2000) Primer3 on the WWW for general users and for biologist programmers. In: Misener, S. \& S.A. Krawetz (Eds). Bioinformatics Methods and Protocols: Methods in Molecular Biology. Humana Press Inc, Totowa (NJ), pp.365-386.

Smith LC, Azumi K, Nonaka M (1999) Complement systems in invertebrates. The ancient alternative and lectin pathways. Immunopharmacol 42:107-120.

Sunyer JO, Lambris JD (1998) Evolution and diversity of the complement system of poikilothermic vertebrates. Immunol Rev 166:39-57.

Sunyer JO, Tort L, Lambris JD (1997) Diversity of the third form of complement, $\mathrm{C} 3$, in fish: functional characterization of five forms of $\mathrm{C} 3$ in the diploid fish Sparus aurata. Biochem J 326:877-881.

Thompson JD (1994) CLUSTAL W: improving the sensitivity of progressive multiple sequence alignment through sequence weighting, position-specific gap 
penalties and weight matrix choice. Nuc Acids Res 22:4673-4680.

Yazawa R, Hirono I, Aoki T (2005) Characterization of promoter activities of four different Japanese flounder promoters in transgenic zebrafish. Mar Biotechnol 21:625-633.

Zapata AG, Torroba M, Varas A, Jiménez E (1997) Immunity in fish larvae. Developments in Biological
Standardizations 90:23-32.

Zarkadis IK, Sarrias MR, Sfyroera G, Sunyer JO, Lambris JD (2001) Cloning and structure of three rainbow trout C3 molecules: a plausible explanation for their functional diversity. Dev Comp Immunol 25:11-24.

Zhu Y, Thangamani S, Ho B, Ding JL (2005) The ancient origin of the complement system. EMBO J 24:382-394. 